\title{
Methyl Substitution Effects on the Proton Chemical Shifts in Benzene *
}

\author{
G. S. REDDY \\ E. I. du Pont de Nemours \& Company, Inc. \\ Explosives Department, Eastern Laboratory, Gibbstown, New Jersey, U.S.A. \\ (Z. Naturforschg. 21 a, 609-615 [1966]; received 16 December 1965)
}

\begin{abstract}
Methyl substitution effects on aromatic and methyl proton chemical shifts in several mono-, di-, and trimethyl benzenes are studied. A new method for obtaining the changes in the ring proton chemical shifts from those of methyl proton shifts at the corresponding positions is used. The extra $\pi$-electron densities in toluene are calculated using the already known relation between the $\pi$-electron densities and the proton shifts in aromatic systems. An inverse relationship is obtained between the ionization potentials and the total methyl effects on the chemical shifts in this series of compounds as one would expect. Dipole moment of toluene is calculated, and a reasonably good agreement is found between the experimentally observed and the calculated dipole moment.
\end{abstract}

Several efforts have been made from time to time to study the substitution effects on chemical shifts and coupling constants. One of the earliest attempts in this line are those of Cavanaugh and DAILEY $^{1}$ who tried to study the effect of multiple methyl substitution in methane. They encountered negative shifts contrary to expectations based on inductive and hyperconjugative effects of the methyl group which eventually was attributed to the anisotropy effect of the added $\mathrm{C}-\mathrm{C}$ bonds ${ }^{2-7}$. SPIEsECKE and SCHNEIDER have studied the substituent effect on both proton and carbon-13 chemical shifts in alkyl ${ }^{8}$ and aromatic ${ }^{9}$ compounds and concluded that diamagnetic anisotropy contributions are very serious and have to be corrected for before attempting to use these parameters for correlations.

REDDY and coworkers ${ }^{10-13}$ have studied the methyl substitution effects on proton chemical shifts in ethylenic and heterocyclic systems and showed that methyl group releases electrons into the $\pi$ system which then rearranges according to the substituents in the system. Their results also showed the extent of electron release by the methyl as measured by the proton chemical shifts is approximately the same in all the systems studied.

* Contribution No. 207 from the Research and Development Division of the Explosives Department of E. I. du Pont de Nemours \& Company.

1 J. R. Cavanaugh and B. P. Dailey, J. Chem. Phys. 34, 1094, 1099 [1961].

2 J. Tilliev, Ann. Phys. Paris 2, 471, 631 [1957].

3 P. T. Narasimhan and M. T. Rogers, J. Chem. Phys. 31, 1302 [1959].

4 G. S. Reddy and J. H. Goldstein, J. Chem. Phys. 38, 2736 [1963].

5 J. I. Musher, J. Chem. Phys. 35, 1159 [1961].

6 A. A. Bothner-By and C. NaAR-Colin, Ann. N.Y. Acad. Sci. 70, 833 [1958].
Considerable work has also been done in estimating $\pi$-electron densities from chemical shift measurements in unsaturated systems. This study involves extension of the substitution effects and also estimating $\pi$-electron densities in methyl benzenes. Eight mono-, di-, and trimethyl substituted benzenes have been studied, and a new technique has been deployed to obtain the methyl substitution effects on the chemical shifts of ring protons from proton chemical shifts and methyl group shifts.

\section{Experimental}

All the spectra were obtained in very dilute solutions (ca. $2-3 \%$ ) in $\mathrm{CCl}_{4}$ with about $1 \%$ tetramethylsilane added to serve as internal reference. Preliminary dilution studies indicated no serious concentration effects on the chemical shifts. Calibrations were carried out by side band technique and the allowed uncertainties in the chemical shifts are $\pm 0.5 \mathrm{cps}$. All the measurements were made on $\mathrm{V}$ a rian Associates 4311-B High Resolution Spectrometer operating at $60 \mathrm{mc} / \mathrm{sec}$ and equipped with a Flux Stabilizer. All the chemical shifts are expressed in cycles per second with respect to tetramethylsilane as internal reference. The centers of the peaks were taken as the chemical shifts wherever the pattern is broad or symmetrically split.

7 G. S. Reddy and J. H. Goldstein, J. Chem. Phys. 39, 3509 [1963].

8 H. Spiesecke and W. G. Schneider, J. Chem. Phys. 35, 722 [1961].

9 H. Spiesecke and W. G. Schneider, J. Chem. Phys. 35, 731 [1961].

10 G. S. Reddy and J. H. Goldstein, J. Am. Chem. Soc. 83, 2045 [1961].

11 G. S. Reddy and J. H. Goldstein, J. Am. Chem. Soc. 83, 5020 [1961].

12 G. S. Reddy, R. T. Hobgood, and J. H. Goldstein, J. Am. Chem. Soc. 84, 336 [1962].

13 G. S. Reddy, L. Mandell, and J. H. Goldstein, J. Chem. Soc. 1963, 1414. 


\section{Results and Discussion}

Table 1 shows all the chemical shifts in the eight methyl benzenes, including that of benzene. $\omega_{\mathrm{ar}}$ and $\omega_{\text {me }}$ are the chemical shifts in cycles per second of the aromatic protons and methyl protons respectively from tetramethylsilane. $\Delta \omega_{\mathrm{ar}}$ is the shift of the aromatic protons for each compound from benzene and denotes the methyl substitution effect. Where there is more than one peak due to different protons shifting to different extents, the number of protons representing that peak is shown in the parentheses after the chemical shift. $\Delta \omega_{\mathrm{me}}$ is the difference in the chemical shift of the methyl protons in the compound under consideration and that in toluene. This denotes the effect of methyl substitution on another methyl group already present in the ring. The last three columns represent the total me- thyl effect on the ring protons, the average effect due to one methyl group calculated as described in the following pages, and the ionization potentials of some of these compounds. Figure 1 represents a plot of the ionization potentials and the total methyl substitution effects. Figure 2 shows the structure of toluene and the additional $\pi$-electron distribution used in calculating the dipole moment.

It has been shown that when a methyl group replaces a proton in ethylene, substituted ethylenes, and some unsaturated ring systems, the other proton chemical shifts move to higher fields ${ }^{10-13}$, indicating that the carbon atoms to which these protons are attached gain electronic charge released into the system by the methyl group by inductive and/or hyperconjugative mechanism. The redistribution of this additional charge in the molecule is different in different molecules, depending on the properties of

\begin{tabular}{|c|c|c|c|c|c|c|c|}
\hline Compound & $\omega_{\mathrm{ar}}$ & $\omega_{\mathrm{me}}$ & $\Delta \omega_{\mathrm{ar}}$ & $\Delta \omega_{\mathrm{me}}$ & $\begin{array}{c}\text { Total Me- } \\
\text { thyl Effect } \\
\left(3 \Sigma \Delta \omega_{\mathrm{me}}\right. \\
\left.\Sigma \Delta \omega_{\mathrm{ar}}\right)\end{array}$ & $\begin{array}{c}\text { Total Effect } \\
\text { No. of } \\
\text { Methyl Groups }\end{array}$ & $\begin{array}{l}\text { Ionization } \\
\text { Potential* } \\
\quad(\mathrm{eV})\end{array}$ \\
\hline & -433.0 & - & - & - & - & - & 9.56 \\
\hline$-\mathrm{CH}_{3}$ & -424.2 & -136.2 & +8.8 & - & 44.0 & 44.0 & 9.23 \\
\hline$-\mathrm{CH}_{3}$ & -418.3 & -130.5 & +14.7 & +5.7 & 93.0 & 46.5 & 9.04 \\
\hline$-\mathrm{CH}_{3}$ & $\begin{array}{l}-415.5(1) \\
-412.8(3)\end{array}$ & -133.8 & $\begin{array}{l}+17.5(1) \\
+20.2(3)\end{array}$ & +2.4 & 92.5 & 46.3 & 9.05 \\
\hline$-n_{3}$ & -416.2 & -132.8 & +16.8 & +3.4 & 87.6 & 43.8 & 8.99 \\
\hline $\mathrm{H}_{3} \mathrm{C}-$ & -400.3 & -131.7 & +32.7 & +4.5 & 138.6 & 46.2 & 8.74 \\
\hline $\begin{array}{l}-\mathrm{CH}_{3} \\
-\mathrm{CH}_{3}\end{array}$ & -409.8 & $\begin{array}{l}-131.3(1) \\
-128.3(2)\end{array}$ & +23.2 & $\begin{array}{r}+4.9(1) \\
+7.9(2)\end{array}$ & 131.7 & 43.9 & - \\
\hline $\begin{array}{l}-\mathrm{CH}_{3} \\
-\mathrm{CH}_{3}\end{array}$ & -410.8 & $\begin{array}{l}-130.7(2) \\
-124.2(1)\end{array}$ & +22.2 & $\begin{array}{r}+5.5(2) \\
+12.0(1)\end{array}$ & 135.6 & 45.2 & - \\
\hline $\mathrm{CH}_{3}$ & & & & & & & \\
\hline
\end{tabular}

* Taken from F. H. Field and J. L. Franklin, J. Chem. Phys. 22, 1895 [1954].

Table 1. Methyl Substitution Effects on Proton Chemical Shifts in Benzene. Numbers in parentheses denote the number of protons giving that peak. 
the atoms present in the ring. Moreover, it has been shown in five- and six-membered heterocyclic systems the methyl effects are long-range, showing that the mechanism of electron release is predominantly hyperconjugative. All these observations are in accordance with the expectations that there should be a linear relationship between the $\pi$-electron density on the carbon and the shifts of the carbon atom and the protons attached to this carbon ${ }^{14-16}$.

FrIedeL and RetcoFsKy ${ }^{17}$ have studied the methyl substitution effects on the $\mathrm{C}^{\mathbf{1 3}}$ chemical shifts in ethylenic systems. They have observed in ethylene that when a proton is replaced by a methyl group, the $\beta$ - $\mathrm{C}^{13}$ resonance shifts to higher field while the $\alpha-C^{13}$ resonance shifts to lower field. This parallels the methyl substitution effect studies carried out by REDDY and coworkers ${ }^{10-12}$ on proton resonances in ethylenic and some heterocyclic systems. It has been shown ${ }^{10-12}$ that in ethylene, when a proton is replaced by a methyl group, the $\beta$-proton resonances shift to higher field by about $0.3-0.42 \mathrm{ppm}$ while the $\alpha$-proton resonance shifts to lower field by about $0.45 \mathrm{ppm}$. The high-field shifts of the $\beta$-protons have been attributed ${ }^{10-12}$ to the $\pi$-electron charge localized on the $\beta$-carbon atom as a result of inductive and/or hyperconjugative release of electrons by the methyl group into the $\pi$-system. At the same time, the low-field shift of the $\alpha$-proton resonance can be attributed mostly to the anisotropy effect of the $\mathrm{C}-\mathrm{CH}_{3}$ bond. Applying the $\mathrm{C}-\mathrm{C}$ bond anisotropy obtained by REDDy and Goldsteis ${ }^{18}$, the effect of the $\mathrm{C}-\mathrm{CH}_{3}$ bond on the $\alpha$-proton is calculated to be of the order of $-0.5 \mathrm{ppm}$, which is approximately the same as the observed low-field shift of the $\alpha$-proton in propylene relative to ethylene. In addition to this anisotropy effect, it is plausible to expect that by inductive and/or hyperconjugative mechanism the methyl group will release electrons into the ethylenic system which polarizes the double bond, and, as a result, the $\alpha$-carbon may have some net positive charge which contributes to the low-field shift of the $\alpha$-proton. The magnitude of this charge is hard to estimate. Fraenkel et al. ${ }^{15}$, and Spiesecke and Schneider ${ }^{19}$ obtained a shift of $+160 \mathrm{ppm}$ in $\mathrm{C}^{\mathbf{1 3}}$ chemical shift for a unit charge localized in the

14 P. L. Corio and B. P. Dailey, J. Am. Chem. Soc. 78, 3043 [1956].

15 G. Fraenkel et al., J. Am. Chem. Soc. 82, 5846 [1960].

16 T. Schaefer and W. G. Schneider, Can. J. Chem. 41, 966 [1963]. $\pi$-orbitals of the carbon and $10 \mathrm{ppm}$ for the directly bonded hydrogen. These results can be incorporated into the methyl substitution effects on proton chemical shifts studied by REDDY and coworkers ${ }^{10-12}$ and the expected effects of methyl substitution on $\mathrm{C}^{13}$ chemical shifts can be calculated. These calculations in ethylenic systems give a shift of +4.8 to +6.8 ppm for the effect of methyl substitution on $\beta$-carbon in ethylenic systems and about $-7.2 \mathrm{ppm}$ for the $\alpha$-carbon. These calculated values agree well with the observed values ${ }^{17}$ of +4.4 to $+6.8 \mathrm{ppm}$ for $\beta$-carbon and -3.3 to $-7.3 \mathrm{ppm}$ for $\alpha$-carbon depending on the other substituents. This is considered as an evidence for the validity of the methyl substitution effects on the proton chemical shifts.

In toluene the pattern of the aromatic proton region is a broad peak with clear indications of complicated structure, suggesting that the chemical shifts of these protons are different and the center of this broad peak is at higher field than in benzene. This shows that on substituting one proton in benzene by a methyl group, all the other protons shifted upfield but to different extents and, since the coupling constants are large compared to the differences in their chemical shifts, the individual chemical shifts cannot be obtained. Since there are five hydrogens in toluene, the total shift of these protons obtained from this average shift is $+44 \mathrm{cps}$. In the case of ortho-xylene, the ortho and meta protons are shifted approximately the same extent giving rise to a broad peak and the center of this peak is taken as the average chemical shift for these protons. In the spectrum of meta-xylene, there are two distinct, though broad, peaks with intensity ratio of $1 / 3$. This is because the proton in between the two methyl groups is shifted differently and does not couple strongly with the other protons in the ring, and hence it is separated from the rest. The other three protons shifting to nearly the same extent and coupling strongly with each other show up as one broad peak. Paraxylene and mesitylene being symmetric molecules with all the aromatic protons equivalent give single peaks for both aromatic and methyl protons. In the case of 1,2,3- and 1,2,4-trimethyl benzenes, there are only one aromatic and two methyl proton peaks,

17 H. L. Retcofsky and R. A. Friedel, Private Communication. 18 G. S. Reddy and J. H. Goldstein, J. Chem. Phys. 38, 2736 [1963] and other references quoted in this reference.

19 H. Spiesecke and W. G. Schneider, Tetrahedron Letters $1961,468$. 
and again the centers of the peaks are taken as the average chemical shifts.

Based on these results, it seems almost impossible to obtain the individual proton chemical shifts from the observed spectra. Unlike the aromatic proton spectra, the methyl group spectra contain either single or double peaks uncomplicated by couplings and whose centers are accurate chemical shifts of the corresponding methyl groups. So, it is possible to obtain the effect of one methyl group on another's chemical shift. In the case of ortho-xylene, where the two methyl groups sterically interfere with each other and perhaps push each other out of plane, the anisotropy effect due to the ring current will definitely change and the observed change in the methyl group shifts due to the other will not be accurate. In some of these molecules where there is no steric hindrance, the methyl group effects are expected to be additive as in other previous cases ${ }^{10-13}$. Thus, in meta-xylene the methyl group chemical shift is at higher field by $2.4 \mathrm{cps}$ than that in toluene. If this is taken as the effect of a methyl group on another methyl group at meta position, in mesitylene where there are two methyl groups at meta position to each methyl group their shift is expected to be about $4.8 \mathrm{cps}$ at higher field from toluene; and from Table 1 , it can be seen this effect is $+4.5 \mathrm{cps}$ which is in good agreement with the expected value. Similarly a para effect of $+3.4 \mathrm{cps}$ is obtained from para-xylene. Again, considering the case of 1,2,4trimethyl benzene, the 4-methyl group experiences effect due to two other methyl groups, one at meta and the other at para positions. The meta effect is seen to be $+2.4 \mathrm{cps}$ in the case of meta-xylene and the para effect is $+3.4 \mathrm{cps}$ in para-xylene. In $1,2,4$ trimethyl benzene, the 4-methyl group is expected to show the combined effect of meta and para methyl groups which is $5.8 \mathrm{cps}$. The observed value is in reasonable agreement with the expected value (see Table 1). Similar reasoning shows that the 2-methyl group shift in 1,2,3-trimethyl benzene should be about $11.5 \mathrm{cps}$ toward higher field from the methyl group in toluene and the experimentally observed value is $+12.0 \mathrm{cps}$, which again is considered to support the additivity of the methyl effects.

In earlier studies on furan, methyl furans, thiophene, and methyl thiophenes ${ }^{11}$, it has been found that a methyl group effect on a second methyl group

20 J. C. Schug and J. C. Deck, J. Chem. Phys. 37, 2618 [1962]. is about one-third the effect of that methyl group on a proton at the same position as the second methyl group. These observations are in complete agreement with the observations of ScHug and $\mathrm{DECK}^{20}$ in hydroxy benzenes. Using this relation, it is possible to obtain the effects of methyl groups on proton chemical shifts in these methyl benzenes from the chemical shifts of the methyl group at the same positions. Thus, in meta-xylene, the effect of a methyl group on the meta-methyl group, which is $+2.4 \mathrm{cps}$, can be converted to the effect of this methyl group on a meta proton. This gives a meta effect of about $+7.0 \mathrm{cps}$. Similarly, in para-xylene, the para effect can be obtained as about $+10 \mathrm{cps}$. From these values for meta and para effects and the effects of the three methyl groups on a proton in 1,3,5-trimethyl benzene, the ortho effect can be calculated as approximately $+10 \mathrm{cps}$. These three values are used to calculate the predicted proton chemical shifts in all these compounds relative to benzene and are compared with the observed shifts in Table 2.

The fact that the methyl group shifts due to another methyl group are approximately a third of those of protons at the same position and vice versa is used to obtain the actual proton shifts and hence the total methyl substitution effects. These total methyl group effects and also the effect due to one methyl group are included in Table 1 . It can be seen that the total effect is proportional to the number of the methyl groups present on the ring, and the effect due to one methyl is approximately the same in all this series of compounds. The uncertainties in the total effect values are believed to be about 5 cps since conversion of methyl shift to aromatic proton shift involves a factor of three. The average methyl group effect (Table 1) is found to be constant within $\pm 1.5 \mathrm{cps}$.

The ionization potential of a molecule is a measure of the ease of dissociating an electron from the molecule; and in this series, the more electrons are released into the $\pi$-electron system by methyl groups the easier to dissociate one of the electrons and hence the lower the ionization potential. It has been pointed out in the beginning that the proton chemical shifts attached to a $\mathrm{sp}^{2}$ carbon seem to be directly proportional to the $\pi$-electron density on that carbon. Then, it is logical to expect a linear correlation between the chemical shifts of the aromatic proton in this series and their ionization potentials. 


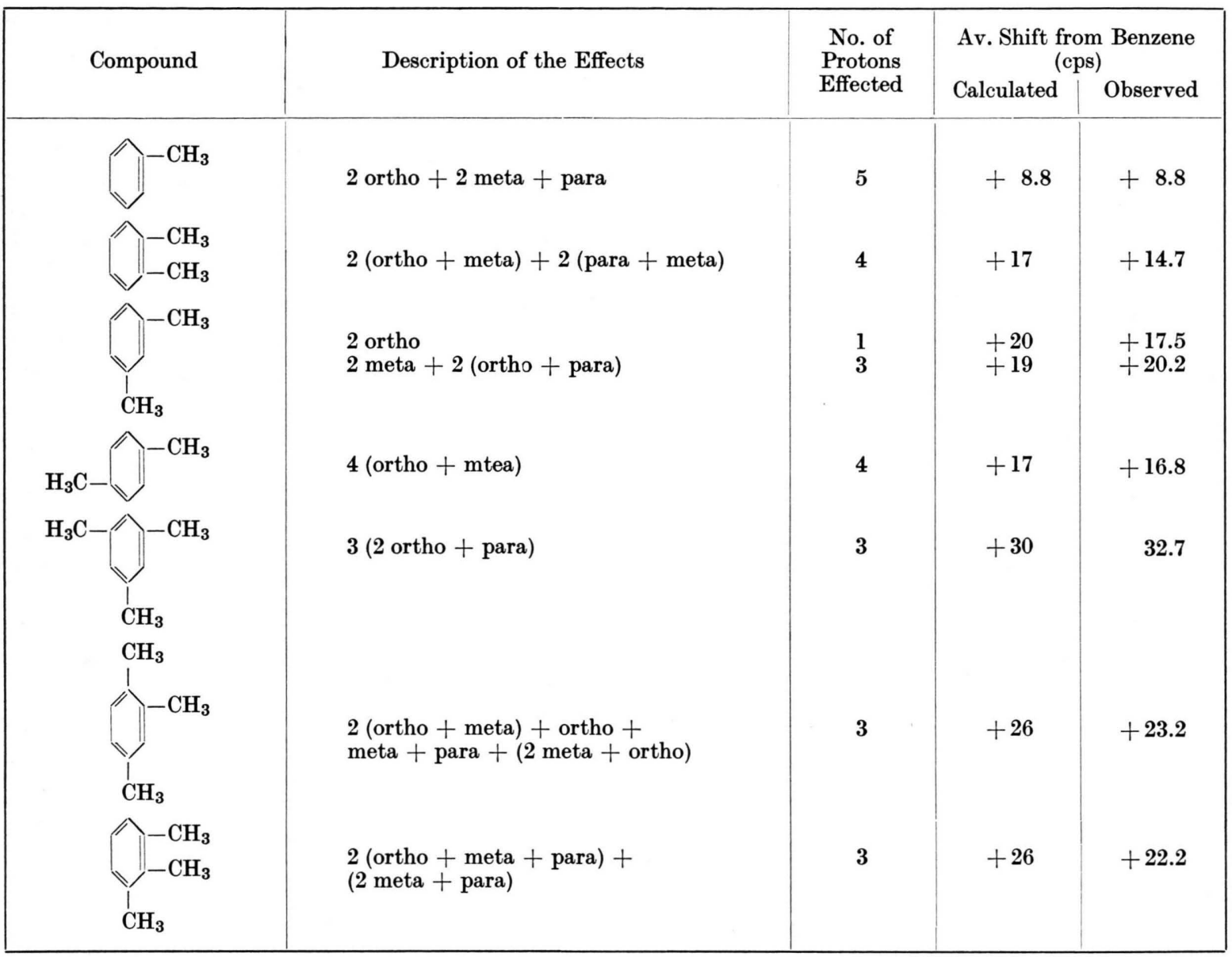

Table 2. Calculated and Observed Average Proton Shifts in Methylbenzenes.

Figure 1 is a plot of the total methyl effect on the aromatic proton chemical shifts calculated as outlined against the ionization potentials, and it can be seen the curve is a straight line with a negative slope as expected.

SPIESECKE and SchNeider ${ }^{19}$ on purely empirical grounds proposed a relation

$$
\Delta \sigma_{\mathrm{A}}=\alpha\left(\varrho_{\mathrm{A}}-1\right)
$$

for the aromatic carbon chemical shifts, where $\Delta \sigma_{\mathrm{A}}$ is the chemical shift of the carbon relative to benzene, $\varrho_{\mathrm{A}}$ is the $\pi$-electron density on the carbon atom, and $\alpha$ is a positive constant. By studying the carbon chemical shifts in systems like $\mathrm{C}_{7} \mathrm{H}_{7}{ }^{+}, \mathrm{C}_{6} \mathrm{H}_{6}$, and $\mathrm{C}_{5} \mathrm{H}_{5}{ }^{-}$, they obtained a value of $+160 \mathrm{ppm}$ for $\alpha$. Fraenkel et al. ${ }^{15}$ have studied proton chemical shifts in similar systems and obtained a value of about $+10 \mathrm{ppm}$ for the shift of a hydrogen for each additional $\pi$-electron on the carbon to which the hydrogen is attached. SchaEfer and SchneIDER ${ }^{16}$ reported a proportionality constant of about 11 . Using this relation and the ortho, para, and meta effects of the methyl group on aromatic proton shifts in toluene, the extra $\pi$-electron densities (presumably arising due to electron release by the methyl group into the ring sysaed) in toluene can be calculated.

However, before this is done, the fact that methyl group protons on a carbon shift only a third as much as a proton on the same carbon has to be taken into account. What this shows is protons removed from the $\pi$-electron site by another carbon also will experience the influence of the $\pi$-electrons but only one third that of the directly attached hydrogen. This fact has to be considered when evaluating the actual shifts of the protons in toluene. If there is a shift of $+10 \mathrm{cps}$ at ortho position 


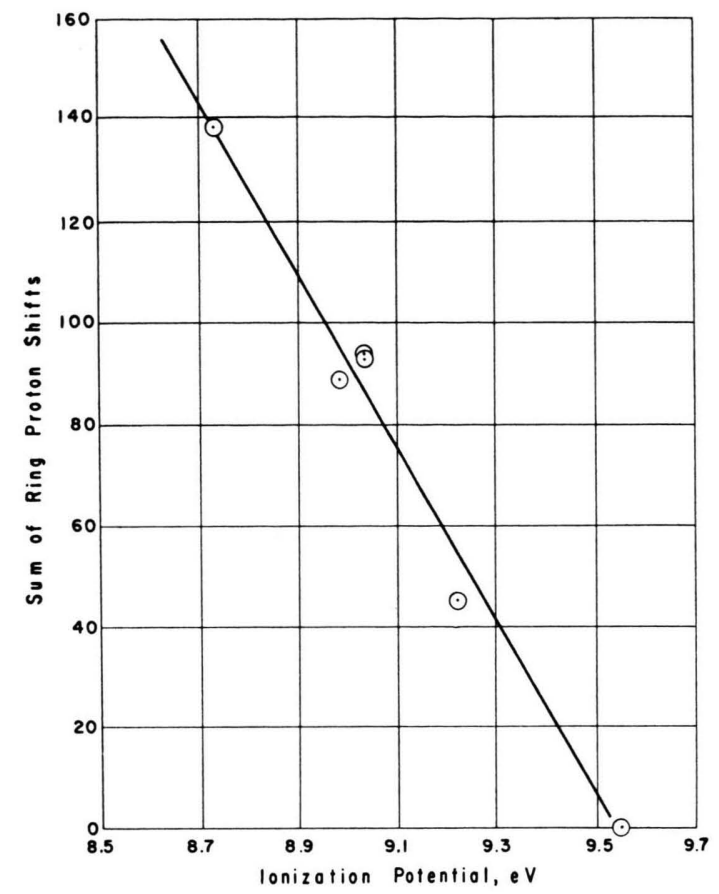

Fig. 1. Plot of Total Methyl Effects vs. Ionization Potential in Methyl Benzenes.

and a shift of $+10 \mathrm{cps}$ at para position due to additional $\pi$-electrons, the meta-hydrogen will shift about $+7 \mathrm{cps}$ because of the additional $\pi$-electron density at ortho and para positions. Accordingly, a correction can be made in the observed shift in the meta position which reduces the meta effect to almost zero. So, the final ortho, meta, and para shifts are about $+10 \mathrm{cps}, 0 \mathrm{cps}$, and $+10 \mathrm{cps}$, respectively. If these shifts are converted to the additional $\pi$-electron densities, one will obtain approximately $0.014,0$, and 0.014 electron for ortho, meta, and para positions, respectively. Assuming that there is no localization of $\pi$-electron charge in the carbon to which the methyl group is attached, the calculated additional electron densities in toluene are as follows:

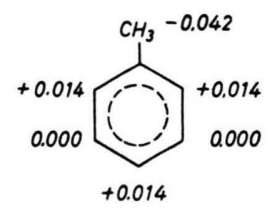

The dipole moment calculated from these $\pi$-electron densities is about $0.7 \mathrm{D}$ compared to the observed value of about $0.4-0.5 \mathrm{D}$. However, this calculated value is due to $\pi$-electrons only and will be modified slightly if $\sigma$-dipole moment is also taken into account. In view of the fairly large uncertainties in the calculated $\pi$-electron densities which neglect changes in $\pi$-electron ring current with substitution and the proportionality constant obtained by FrAENKEL et al. ${ }^{15}$ the agreement between the calculated and observed dipole moments is considered very reasonable.

The additional $\pi$-electron densities obtained in this study show approximately equal negative charge at ortho and para positions and almost no charge at meta position. SANDel and Freedman ${ }^{21}$ studied

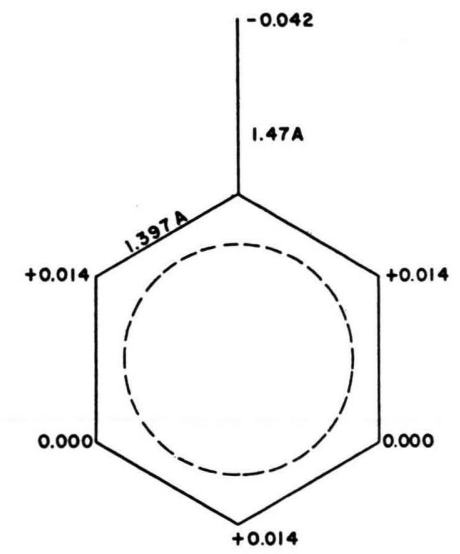

Fig. 2. Bond Lengths and additional $\pi$-Electron Densities used in Calculating the Dipole Moment of Toluene.

the NMR spectra of some arylmethyl carbanions and were able to calculate the $\pi$-electron densities in benzyl anion. Since benzyl anion has a unit negative charge on the methyl group which will be released and redistributed in the ring, this situation is analogous to toluene except that the amount of charge released by methyl group in toluene is much smaller than that in benzyl anion. However, it is expected that the redistribution of this charge in the phenyl ring will be in the same order, differing only in magnitude. Table 3 includes the results obtained for $\mathrm{C}_{6} \mathrm{H}_{5} \mathrm{CH}_{2}^{-} \mathrm{Li}^{+}$by different methods, along with the results obtained in the present study for toluene. It has already been pointed out that the protons at meta positions will experience approximately a third the influence experienced by ortho and para protons due to the charge localized at ortho- and paracarbons. If this is taken into account, SANDEL and Freedman's results can be modified to give values

21 V. R. Sandel and H. H. Freedman, J. Am. Chem. Soc. 85, 2328 [1963]. 


\begin{tabular}{|c|c|c|c|c|}
\hline \multirow{2}{*}{ Position } & $\begin{array}{c}\text { NMR } \\
\text { Method } \\
\text { (Ref. } 21)\end{array}$ & $\begin{array}{c}\text { SCF } \\
\text { MO }\end{array}$ & $\begin{array}{c}\text { LCAO } \\
\text { MO }\end{array}$ & $\begin{array}{c}\text { Present } \\
\text { Study in } \\
\text { Toluene }\end{array}$ \\
\hline \multirow{2}{*}{ ortho } & $0.12(0.12)$ & 0.14 & 0.08 & 0.014 \\
meta & $0.10(0.00)$ & 0.07 & 0.00 & 0.00 \\
para & $0.18(0.18)$ & 0.23 & 0.08 & 0.014 \\
\hline
\end{tabular}

Table 3. $\pi$-Electron Densities in $\mathrm{C}_{6} \mathrm{H}_{5} \mathrm{CH}_{2}{ }^{-} \mathrm{Li}^{+}$and $\mathrm{C}_{6} \mathrm{H}_{5} \mathrm{CH}_{3}$.

in parentheses in Column 2 of Table 3. So, it is believed that the results of SANDEL and Freedman actually show that the meta effect is almost zero and ortho and para effects are approximately the same, which agrees well with the present study.

Since this work was completed, complete analysis of the NMR spectrum of toluene has been carried out by $\mathrm{WU}_{\mathrm{U}}$ and DAILEY ${ }^{22}$ at $100 \mathrm{mc} / \mathrm{sec}$ and Bovey et al. ${ }^{23}$ at $200 \mathrm{mc} / \mathrm{sec}$. The chemical shifts obtained by these authors for ortho, meta, and para hydrogens in toluene are in complete agreement with the values predicted in this work.

22 T. K. Wu and B. P. Dailey, J. Chem. Phys. 41, 2796 [1964].

23 F. A. Bovey, F. P. Hood, III, E. Pier, and H. E. Weaver, J. Am. Chem. Soc. 87, 2060 [1965].

\title{
Dielektrische Untersuchungen an kristallinflüssigen Phasen im Mikrowellenbereich
}

\author{
Teil II: Messungen an einigen 4,4'-Di-n-alkoxy-azoxybenzolen
}

\author{
Albert Axmann \\ Institut für Elektrowerkstoffe, Freiburg i. Br. \\ (Z. Naturforschg. 21 a, 615-620 [1966] ; eingegangen am 8. Januar 1966)
}

\begin{abstract}
Bei Frequenzen von ca. $10 \mathrm{GHz}, 20 \mathrm{GHz}$ und $40 \mathrm{GHz}$ werden von 4,4'-Di-n-methoxy-(p-Azoxyanisol), -butoxy-, hexoxy- und -heptoxy-azoxybenzol die komplexen Hauptdielektrizitätskonstanten $\varepsilon_{1}^{*}$ und $\varepsilon_{2}^{*}$ der kristallinflüssigen Phase sowie die komplexe Dielektrizitätskonstante $\varepsilon^{*}$ is der normalflüssigen Phase gemessen. Die mittlere Polarisierbarkeit des Gesamtmoleküls und das Dipolmoment werden berechnet, die Dipolrelaxationszeiten für die nematische und die isotrope Phase angegeben und diskutiert.
\end{abstract}

In Teil $\mathrm{I}^{1}$ wurde eine Apparatur zur Messung der komplexen Dielektrizitätskonstanten $\varepsilon^{*}$ is der normalflüssigen Phase und der komplexen Hauptdielektrizitätskonstanten $\varepsilon_{1}^{*}$ und $\varepsilon_{2}^{*}$ (parallel und senkrecht zur Achse der kristallinflüssigen Ordnung) von nematischen Schichten, die durch ein Magnetfeld von 4,5 kGauß orientiert sind, beschrieben. Mit dieser wurden bei Frequenzen von ca. $10 \mathrm{GHz}, 20 \mathrm{GHz}$ und $40 \mathrm{GHz}$ Messungen an 4,4'-Di-n-methoxy(p-Azoxyanisol), -butoxy-, -hexoxy- und heptoxyazoxybenzol durchgeführt. Von diesen Verbindungen liegen ausführliche Messungen bei Radiofrequenzen $^{2-4}$ und von p-Azoxyanisol ${ }^{5,6}$ einige im Mikrowellengebiet vor. p-Azoxyanisol wurde von der Firma S ch u chardt, München, bezogen und aus einem Methanol-Benzol-Gemisch umkristallisiert und chromatographisch auf Reinheit geprüft. Die

1 A. Axmann, Z. Naturforschg. 21 a, 290 [1966].

2 W. MaIer u. G. MeIer, Z. Naturforschg. 16 a, 470 [1961].

3 W. Maier u. G. Meier, Z. Naturforschg. 16 a, 1200 [1961].

4 H. WeIse, Diplomarbeit Freiburg 1965.

5 E. F. Carr u. R. D. Spence, J. Chem. Phys. 22, 1481 [1954]. übrigen Substanzen wurden nach GABLER $^{7}$ durch elektrolytische Reduktion der entsprechenden 1-Nitro-4-alkoxy-benzole hergestellt und durch Adsorption an $\mathrm{AL}_{2} \mathrm{O}_{3}$ mit darauffolgender Umkristallisation aus einem Mehanol-Benzol-Gemisch gereinigt. Die Umwandlungspunkte sind in Tab. 1 aufgeführt.

\begin{tabular}{|c|c|c|c|}
\hline -alkyloxy- & $\begin{array}{c}\text { Schmelz- } \\
\text { punkt } \\
{ }^{\circ} \mathrm{C}\end{array}$ & $\begin{array}{c}\text { Klärpunkt } \\
{ }^{\circ} \mathrm{C}\end{array}$ & $\begin{array}{c}\text { Umwand- } \\
\text { lungspunkt } \\
\text { smektisch/ } \\
\text { nematisch } \\
{ }^{\circ} \mathrm{C}\end{array}$ \\
\hline $\begin{array}{c}\text {-methyloxy- } \\
\text {-butyloxy- }\end{array}$ & $\begin{array}{c}118,0 \\
\text {-hexyloxy- }\end{array}$ & $\begin{array}{c}103,0 \\
\text {-heptyloxy- }\end{array}$ & $\begin{array}{c}135,3 \\
137,4\end{array}$ \\
\hline
\end{tabular}

Tab. 1. Phasenumwandlungspunkte der untersuchten 4,4'-Din-alkoxy-azoxybenzole.

B E. F. Carr, J. Chem. Phys. 37, 104 [1962].

7 R. Gabler, Über den Einfluß des Molekülbaus auf die kristallinflüssigen Eigenschaften von Kohlenstoffverbindungen, Verlag Dittert \& Co., Dresden 1939. 